\title{
Clinical Experience with Insulin Detemir in Patients with Type 2 Diabetes from the Near East Countries
}

\author{
Akram Echtay • Anat Tsur • Mohammad I. Hasan • M. Omar Abu-Hijleh • \\ Nidal Al Khatib • Emile Andari • Paola Atallah • Saleem Qureshi • Jamal Zafar • \\ Levent Sandalci $\cdot$ Asude Ademogulları $\cdot$ Jihad Haddad $\cdot$ Bracha Dagan
}

To view enhanced content go to www.diabetestherapy-open.com

Received: August 19, 2013 / Published online: October 10, 2013

(c) The Author(s) 2013. This article is published with open access at Springerlink.com

\section{ABSTRACT}

Introduction: This study aimed at determining the clinical safety and efficacy of insulin detemir (IDet) in combination with oral antidiabetic drugs (OADs) in type 2 diabetes (T2D)

Clinical Trial Registration Number: NCT00842192.

A. Echtay $(\bowtie)$

Rafic Hariri University Hospital, Beer Hassan, Beirut, Lebanon

e-mail: akramechtay@hotmail.com

A. Tsur

Clalit Health Services, Jerusalem, Israel

M. I. Hasan

Diabetic Institute of Pakistan, Lahore, Pakistan

M. O. Abu-Hijleh

Jordan Center for Diabetes and Endocrinology, Jordan Hospital Medical Center, Amman, Jordan

\section{N. Al Khatib}

Endocrinology Clinic, Islamic Hospital, Amman, Jordan

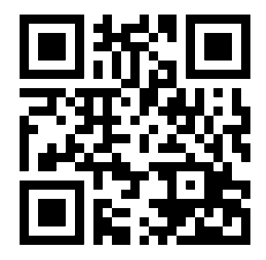

Enhanced content for this article is

available on the journal web site:

www.diabetestherapy-open.com patients from four Near East Countries (Israel, Jordan, Pakistan and Lebanon).

Methods: This prospective observational study included T2D patients previously on OADs and newly diagnosed patients initiating IDet with or without OADs, at the discretion of physicians. Safety objectives included evaluation of hypoglycemia and adverse drug reactions (ADRs) from baseline to Week 24. Efficacy

E. Andari

Notre Dame de Secours Hospital, Byblos, Lebanon

P. Atallah

Saint Georges University Medical Hospital,

Achrafieh, Lebanon

S. Qureshi

KRL Hospital, Islamabad, Pakistan

J. Zafar

Pakistan Institute of Medical Sciences, Islamabad, Pakistan

L. Sandalci · A. Ademogulları

Novo Nordisk Business Area Near East, Istanbul, Turkey

J. Haddad

Division of Endocrinology, Prince Hamazeh

Hospital, Amman, Jordan

B. Dagan

Clalit Health Services, Afula, Israel 
outcomes included baseline to Week 24 changes in glucose control parameters (glycated hemoglobin $\left[\mathrm{HbA}_{1 \mathrm{c}}\right]$, fasting plasma glucose [FPG] and post-breakfast post-prandial plasma glucose [PPPG]). Change in body weight during this period was also assessed.

Results: A total of 2,155 patients (mean \pm SD: age $57.1 \pm 11.0$ years, BMI $29.4 \pm 5.1 \mathrm{~kg} / \mathrm{m}^{2}$, average diabetes duration $9.2 \pm 5.4$ years) were included. IDet dose at baseline was 0.20 $\pm 0.09 \mathrm{U} / \mathrm{kg}$ titrated up to $0.34 \pm 0.14 \mathrm{U} / \mathrm{kg}$ by Week 24. From baseline to Week 24, the total number of hypoglycemic episodes increased from 1.30 to 1.37 events/patient-year, while major hypoglycemic episodes decreased from 0.15 to 0.02 events/patient-year. A total of 9 ADRs were reported, of which one event was a serious ADR. Statistically significant improvements in glucose control were reported from baseline to Week $24\left(\mathrm{HbA}_{1 \mathrm{c}}\right.$ : $9.6 \pm 1.6 \%$ vs. $7.6 \pm 1.1 \%$; FPG: $201.5 \pm 59.5$ $\mathrm{mg} / \mathrm{dL}$ vs. $124.9 \pm 31.6 \mathrm{mg} / \mathrm{dL}$; PPPG: $264.2 \pm$ $65.7 \mathrm{mg} / \mathrm{dL}$ vs. $167.2 \pm 36.8 \mathrm{mg} / \mathrm{dL}$; all $p<$ 0.0001). Body weight did not change significantly after 24 weeks of IDet therapy.

Conclusion: IDet therapy in combination with OADs improved glycemic control without increasing the risk of hypoglycemia or weight gain.

Keywords: Insulin detemir; Near East; Observational study; Type 2 diabetes

\section{INTRODUCTION}

Managing type 2 diabetes (T2D) is a challenging task due to the continual decline in beta-cell function that occurs. This progressive debilitating condition ultimately mandates the use of insulin in most, if not all patients [1]. Timely initiation and active intensification of insulin is highly recommended to decrease the risk of longterm complications [2]. The American Diabetes Association recommends a target glycated hemoglobin $\left(\mathrm{HbA}_{1 \mathrm{c}}\right)$ level of $<7.0 \%$ as an established standard of good glycemic control [3]. Despite these guidelines, it has been observed that initiation and intensification of insulin in routine clinical practice is often delayed over fears of hypoglycemia, weight gain and effects on patients' quality of life (QoL) [1, 4]. Other factors such as insulin availability, needle phobia and economic considerations are also possible barriers that can have a significant impact on patient adherence to treatment [5].

Conventional basal insulins, such as neutral protamine Hagedorn (NPH) and insulin glargine have variable absorption kinetics resulting in increased within-patient blood glucose variability and an associated risk of hypoglycemia [6, 7]. Also, the weight gain associated with conventional insulin therapy may increase blood pressure and worsen lipid profiles [8]. The development of long-acting basal insulin analogs, such as insulin detemir (IDet), with improved pharmacokinetics has been shown to have a positive effect on the balance between effective glycemic control and hypoglycemic risk [9].

IDet is able to closely mimic endogenous insulin secretion and has a prolonged timeaction profile due to its self-association and albumin-binding properties [10]. It is prescribed once- or twice-daily as an adjunct to oral antidiabetic drugs (OADs), glucagon-like peptide-1 analogs or as combination therapy with shortor rapid-acting insulins [11]. Previously, it has been demonstrated that IDet therapy results in lower within-subject variability of fasting plasma glucose (FPG) when compared with $\mathrm{NPH}$ insulin therapy [12]. Also, the 
effectiveness of glucose control with IDet has been observed with a reduced risk of hypoglycemia and no concerns about weight gain $[13,14]$.

The clinical benefits of insulin analogs, including IDet, could become an integral part of managing $\mathrm{T} 2 \mathrm{D}$, a disease that has reached epidemic proportions worldwide [15]. Developing countries from the Near East region face a serious socioeconomic burden of increasing diabetes incidence. According to the International Diabetes Federation, in 2012, the prevalence of diabetes in Israel, Jordan, Lebanon and Pakistan was 7.85\%, 11.62\%, $17.04 \%$ and $7.89 \%$, respectively [15]. Additionally, Lebanon is listed among the top 10 countries for diabetes prevalence worldwide [16]. Active measures to control and manage this disease are warranted. In order to increase awareness and provide appropriate guidance on T2D management the availability of local clinical data is essential. This 24-week observational study was thus conducted in T2D patients from four Near East Countries (Israel, Lebanon, Jordan and Pakistan) with an aim to evaluate the post-authorization experience with IDet in combination with OADs.

\section{METHODS}

\section{Study Design}

This multinational, prospective, observational study evaluated the safety and efficacy of 24 weeks of treatment with IDet $\left(\right.$ Levemir $^{\circledR}$, Novo Nordisk, Bagsvaerd, Denmark) in T2D patients from four Near East countries (Israel, Jordan, Lebanon and Pakistan) between April 2009 and August 2010. Patients prescribed IDet at the discretion of their consulting physicians, based on clinical judgement and countryspecific Summary of Product Characteristics or Product Information reports, were enrolled in the study. Any subsequent changes in dose or frequency of administration of IDet or OADs were determined by the physician. IDet was commercially available and prescribed in accordance with local healthcare regulations. There were no predefined study procedures and all assessments were performed as part of routine clinical care. The physicians evaluated patients at baseline, the interim visit (approximately 12 weeks post-baseline visit) and final visit (approximately 24 weeks postbaseline visit).

\section{Patients}

This study included any T2D patient previously treated with one or more OADs (metformin, sulfonylureas, repaglinide, thiazolidinediones) or newly diagnosed T2D patients starting IDet \pm OAD therapy. Patients currently being treated with IDet or any other insulin regimen, including bolus therapy, were excluded from the study. Also, patients with a reported hypersensitivity to IDet or any of its excipients were not included in this study. The study did not include women who were pregnant, breast feeding, had the intention of becoming pregnant within 6 months or those of childbearing potential and not using adequate contraceptive methods.

All procedures followed were in accordance with the ethical standards of the responsible committee on human experimentation (institutional and national) and with the Helsinki Declaration of 1975 , as revised in 2000 and 2008. Informed consent was obtained from all patients for being included in the study. 


\section{Outcomes}

The primary safety objective was to evaluate change in the number of hypoglycemicepisodes from the 4 weeks preceding the baseline visit compared with after 24 weeks of IDet treatment. Information on hypoglycemic episodes was collected based on patients' recall of the last 4 weeks before baseline and Week 24. Minor hypoglycemic events were described as symptoms of hypoglycemia with confirmation by plasma glucose measurement $<3.1 \mathrm{mmol} / \mathrm{L}$ $(56 \mathrm{mg} / \mathrm{dL})$ and which was handled by the patient himself/herself, or any asymptomatic plasma glucose level $<3.1 \mathrm{mmol} / \mathrm{L}$ ( $56 \mathrm{mg} / \mathrm{dL})$. Nocturnal hypoglycemic events were defined as individualized symptomatic events consistent with hypoglycemia that occurred while the patient was asleep, between bedtime after the evening insulin injection and before getting up in the morning (if relevant, before morning determination of FPG and before morning injection). Severe central nervous system symptoms consistent with hypoglycemia in which the patient was unable to treat himself/ herself, or reversal of symptoms after either glucagon or intravenous glucose administration were categorized as major hypoglycemic events. Additionally, hypoglycemia due to the fasting regimen, Ramadan, was also reported. The incidence of adverse drug reactions (ADRs) was reported as the secondary safety objective.

The primary efficacy endpoint was to determine the effects of IDet on glycemic control as reflected by changes in $\mathrm{HbA}_{1 \mathrm{c}}$ levels after 24 weeks of treatment. Secondary endpoints included evaluation of the number of patients achieving $\mathrm{HbA}_{1 \mathrm{c}}$ targets of $<7.0 \%$ and $\leq 6.5 \%$; changes in FPG, post-breakfast postprandial plasma glucose (PPPG) and body weight; and FPG variability from baseline to Week 24. FPG variability was defined as the standard deviation (SD) of the three most recent FPG values.

\section{Statistical Analysis}

Approximately 2,000 patients were considered sufficient to evaluate primarily the safety of IDet in this study. This sample size was estimated to provide a statistical power greater than $99 \%$ to detect a $1.0 \%$ change in $\mathrm{HbA}_{1 \mathrm{c}}$ from baseline based on a standard deviation of 1.2 and an estimated drop-out rate of $20 \%$.

Patients who had received at least one dose of IDet and reported any post-baseline data were included in the full analysis set. Demographic characteristics, $\mathrm{HbA}_{1 \mathrm{c}}$, FPG, PPG and body weight were summarized using descriptive statistics. Categorical data were summarized using the number ( $n$ ) and percentage. The paired $t$ test was used to analyze the change from baseline to Week 24 in $\mathrm{HbA}_{1 \mathrm{c}}$, FPG, PPPG and body weight. The change in the proportion of patients with $\mathrm{HbA}_{1 \mathrm{c}}<7.0 \%$ or $\leq 6.5 \%$ was evaluated using the Chi square test. All statistical analyses were based on two-sided tests and a significance level of $\alpha=0.05$. All data were analyzed using SAS Version 9.1.3 $\left(\mathrm{SAS}^{\circledR}\right.$ Institute Inc., Cary, North Carolina, USA).

\section{RESULTS}

\section{Patient Disposition}

Of the 2,155 patients enrolled, 2,106 (97.7\%) were exposed to the study drug. A total of 1,843 $(85.5 \%)$ patients completed the study and 263 $(12.2 \%)$ withdrew from the study. The reasons for premature discontinuation from the study included lost contact (146 patients, 6.8\%), ADRs (6 patients, $0.3 \%$ ) and other reasons 
(111 patients, 5.2\%), which included noncompliance, consent withdrawal and therapy switch to OADs or other insulins. The demographic characteristics along with OAD use at baseline for the entire cohort and patients that withdrew are presented in Table 1. Prior to study enrolment, biguanides (84.9\%), sulfonylureas $(78.0 \%)$ and thiazolidinediones (17.9\%) were the most commonly administered OADs. The most common physician's reason to initiate IDet therapy was to improve glycemic control in 2,038 patients (96.8\%), while the other common reasons were to reduce plasma glucose variability and to control unstable diabetes in 827 (39.3\%) and $656(31.1 \%)$ patients, respectively.

Table 1 Patient demographics and baseline characteristics

\begin{tabular}{|c|c|c|}
\hline Parameters & $\begin{array}{l}\text { Entire } \\
\text { cohort }^{a}\end{array}$ & Withdrawals \\
\hline$n$ & 2,106 & 263 \\
\hline \multicolumn{3}{|l|}{ Sex $(\%)$} \\
\hline Male & 55.1 & 51.7 \\
\hline Female & 44.9 & 48.3 \\
\hline Age (years) ${ }^{b}$ & $57.1(11.0)$ & $57.1(11.8)$ \\
\hline Body weight $(\mathrm{kg})^{\mathrm{b}}$ & $80.2(14.1)$ & $80.5(13.6)$ \\
\hline BMI $\left(\mathrm{kg} / \mathrm{m}^{2}\right)^{\mathrm{b}}$ & $29.4(5.1)$ & $29.7(5.0)$ \\
\hline $\begin{array}{l}\text { Diabetes duration } \\
\text { (years) }^{\mathrm{b}}\end{array}$ & $9.2(5.4)$ & $9.5(5.8)$ \\
\hline $\mathrm{HbA}_{1 \mathrm{c}}(\%)^{\mathrm{b}}$ & $9.6(1.6)$ & $9.7(1.8)$ \\
\hline \multicolumn{3}{|c|}{ OADs at baseline, $n(\%)$} \\
\hline Biguanides & $1,687(80.1)$ & $263(100.0)$ \\
\hline Sulfonylureas & $1,497(71.1)$ & $155(58.9)$ \\
\hline Thiazolidinediones & $292(13.9)$ & $21(8.0)$ \\
\hline
\end{tabular}

$B M I$ body mass index, $H b A_{1 c}$ glycated hemoglobin $\mathrm{A}_{1 \mathrm{c}}$, $O A D$ oral anti-diabetic drug, $S D$ standard deviation

a Patients had received at least one dose of IDet

b Data are mean (SD)

\section{Insulin Dose}

Mean $( \pm$ SD $)$ IDet dose at baseline was $0.20 \pm 0.09 \mathrm{U} / \mathrm{kg} \quad(15.6 \pm 7.1 \mathrm{U} /$ day $)$, titrated up to $0.34 \pm 0.14 \mathrm{U} / \mathrm{kg}(27.1 \pm 11.4 \mathrm{U} /$ day $)$ by Week 24.

\section{Hypoglycemia}

Overall, major, minor and nocturnal hypoglycemic events and hypoglycemic events due to the fasting regimen, Ramadan, are reported in Table 2 . The incidence of hypoglycemia (all events) appeared to increase slightly during the study, from 1.37 events/ patient-year at Week 24 compared with 1.30 events/patient-year at baseline. The rate of major hypoglycemic episodes appeared to be lower at Week 24 (0.02 events/patient-year) in comparison with baseline (0.15 events/patientyear). The rate of nocturnal hypoglycemia appeared similar at baseline and Week $24(0.40$ and 0.39 events/patient-year, respectively). The rate of hypoglycemia due to fasting in Ramadan also appeared similar at baseline and Week 24 (0.07 and 0.06 events/patient-year, respectively).

Table 2 Baseline and 24-week event rates of hypoglycemia

\begin{tabular}{lll}
\hline $\begin{array}{l}\text { Hypoglycemic } \\
\text { event }\end{array}$ & $\begin{array}{l}\text { Baseline (events/ } \\
\text { patient-year) }\end{array}$ & $\begin{array}{l}\text { Week 24 (events/ } \\
\text { patient-year) }\end{array}$ \\
\hline Total & & \\
All events & 1.30 & 1.37 \\
Major & 0.15 & 0.02 \\
Minor & 1.15 & 1.30 \\
Nocturnal & 0.40 & 0.39 \\
$\begin{array}{l}\text { Due to fasting } \\
\text { regimen }\end{array}$ & 0.07 & 0.06 \\
\hline
\end{tabular}

Hypoglycemic episodes were collected based on patients' recall of the last 4 weeks before baseline and Week 24

${ }^{a}$ Fasting regimen at Ramadan 


\section{Adverse Drug Reactions}

A total of 9 ADRs were reported in 9 patients $(0.4 \%)$ during the study. Of these, one event in one patient was a serious ADR of chronic renal failure. In all, 12 treatment emergent adverse events were reported in 11 patients $(0.5 \%)$. Of the 6 ADRs that led to discontinuation of IDet, 5 events (3 drug hypersensitivity/drug allergy; 1 pruritus; 1 drug eruption) were considered probably related to IDet, while one event of bone pain was considered possibly related to IDet. These events were mild to moderate in intensity.

\section{Body Weight}

Mean body weight did not change significantly from baseline $(80.5 \pm 13.8 \mathrm{~kg})$ to Week 24 $(80.4 \pm 13.5 \mathrm{~kg}, p=0.567)$.

\section{Glucose Control}

Mean $\mathrm{HbA}_{1 \mathrm{c}}$ levels improved significantly from $9.6 \pm 1.6 \%$ at baseline to $7.6 \pm 1.1 \%$ at Week 24 (mean change, $-2.0 \pm 1.6 \%, \quad p<0.0001$ ) (Table 3). $\mathrm{HbA}_{1 \mathrm{c}}<7.0 \%$ was reported in 424 of 1,574 patients $(26.9 \%)$ at Week 24 compared with 29 of 1,896 patients (1.5\%) at baseline. $\mathrm{HbA}_{1 \mathrm{c}} \leq 6.5 \%$ was achieved by 16 of 1,896 patients $(0.8 \%)$ at baseline, increasing to 189 of 1,574 patients (12.0\%) by Week 24 .

At Week 24, there was a statistically significant mean decrease of $76.6 \pm 62.5 \mathrm{mg} / \mathrm{dL}$ in FPG $(p<0.0001$, Table 3$)$. The decrease in FPG variability from baseline to Week 24 was statistically significant $(-10.1 \pm 19.8 \mathrm{mg} / \mathrm{dL}$, $p<0.0001)$ as was the reduction in postbreakfast PPPG levels (Week 24, 167.2 \pm $36.8 \mathrm{mg} / \mathrm{dL}$ vs baseline, $264.2 \pm 65.7 \mathrm{mg} / \mathrm{dL}$, $p<0.0001$, Table 3).

\section{DISCUSSION}

Previously, it has been established that adding basal insulin to existing OAD therapy is an effective treatment strategy to manage uncontrolled T2D [17]. This study assessed the effects of IDet in combination with OADs in patients with T2D from Israel, Lebanon, Jordan and Pakistan. Introducing IDet therapy was well tolerated and resulted in marked improvements in glucose control after 24 weeks.

Baseline glycemic control in this cohort was poor. The average baseline $\mathrm{HbA}_{1 \mathrm{c}}$ level was 9.6\%, while FPG and post-breakfast PPPG levels were $201.5 \mathrm{mg} / \mathrm{dL}$ and $264.2 \mathrm{mg} / \mathrm{dL}$, respectively. This calls for an imperative need to design and implement more aggressive strategies to optimize T2D management in

Table 3 Baseline and 24-week data for glycemic parameters

\begin{tabular}{lrrrrc}
\hline Parameter & \multicolumn{1}{c}{$\boldsymbol{n}$} & \multicolumn{1}{c}{ Baseline } & Week 24 & Change & $\boldsymbol{p}$ value \\
\hline $\mathrm{HbA}_{\mathrm{lc}}(\%)$ & 1,460 & $9.6(1.6)$ & $7.6(1.1)$ & $-2.0(1.6)$ & $<0.0001$ \\
FPG $(\mathrm{mg} / \mathrm{dL})$ & 1,532 & $201.5(59.5)$ & $124.9(31.6)$ & $-76.6(62.5)$ & $<0.0001$ \\
FPG variability (mg/dL) & 443 & $22.1(18.6)$ & $12.0(11.7)$ & $-10.1(19.8)$ & $<0.0001$ \\
PPPG (mg/dL) & 940 & $264.2(65.7)$ & $167.2(36.8)$ & $-97.1(68.9)$ & $<0.0001$ \\
\hline
\end{tabular}

Data are mean (SD). FPG variability was defined as the SD of the three most recent FPG values $F P G$ fasting plasma glucose, $H b A_{1 c}$ glycated hemoglobin $\mathrm{A}_{1 c}, P P P G$ postprandial plasma glucose, $S D$ standard deviation 
routine clinical practice in the Near East countries.

Initiating IDet significantly improved $\mathrm{HbA}_{1 \mathrm{c}}$, FPG and PPPG following 24 weeks of treatment. A total of 424 patients (26.9\%) achieved the target $\mathrm{HbA}_{1 \mathrm{c}}$ level of $<7.0 \%$ with 189 patients $(12.0 \%)$ achieving the more aggressive target of $\mathrm{HbA}_{1 \mathrm{c}} \leq 6.5 \%$ after 24 weeks of treatment. Additionally, there were indications of a reduction in plasma glucose fluctuation as assessed by evaluating the standard deviations of the three most recent FPG levels. These improvements were seen alongside a low risk of hypoglycemia. As an expected outcome with first-time insulin initiation, there was a marginal increase in the rate of overall hypoglycemia from baseline to Week 24 . However, the incidence of major hypoglycemia was lower at Week 24 compared with baseline. The incidence of major hypoglycemia could be reduced due to initial responses to a change in therapy. Also, this study included only insulin-naïve patients who have a much lower rate of hypoglycemia compared with prior insulin users [18]. Nevertheless, we also acknowledge that a recall bias may have been introduced that could have masked the actual incidence of hypoglycemia. The clinical safety and efficacy of treatment was demonstrated without administering high doses of IDet $(0.20 \mathrm{U} / \mathrm{kg}$ to $0.34 \mathrm{U} / \mathrm{kg})$ throughout the study period. Although the actual IDet dose in this study was lower than that reported in interventional trials $[19,20]$, a significant change in glycemic control was observed. This positive response to therapy could also encourage physicians to resort to more active therapy intensification, leading to enhanced management of T2D.

Previously, it has been reported that every 2.5\% decrease in $\mathrm{HbA}_{1 \mathrm{c}}$ is associated with a weight gain of $\sim 5 \mathrm{~kg}$ [21]. In contrast, average body weight remained fairly constant in our study despite a significant $2.0 \%$ decrease in mean $\mathrm{HbA}_{1 \mathrm{c}}$ level. Raslová et al. [22] also demonstrated that patients on IDet experienced less weight gain than those on NPH insulin in a pooled analysis of 900 patients with T2D. Several theories have been proposed to justify the low weight gain observed with IDet therapy. The low glucose variability reported with IDet therapy may minimize defensive snacking resulting in decreased weight gain. Also, IDet may induce the satiety signaling mechanism in the central nervous system or suppress adipogenesis in the peripheral tissues due to its albumin-binding properties [23]. IDet has a prolonged therapeutic action owing to its strong tendency to self-associate and remain highly bound to albumin in the subcutaneous depot [24]. Nevertheless, the exact mechanism of action resulting in low weight gain following IDet therapy has yet to be elucidated.

The United Kingdom Prospective Diabetes study demonstrated that $53 \%$ of patients treated with sulfonylurea monotherapy required insulin over a period of 6 years [25]. The gradual decline in beta-cell mass and function in patients with T2D is correlated with an increase in $\mathrm{HbA}_{1 \mathrm{c}}$ levels, even after the use of more than one OAD [26]. Hence, insulin therapy becomes mandatory for all patients. However, intensification with insulin therapy also increases the risk of hypoglycemia. Our study demonstrates that initiating IDet therapy effectively enhances glycemic control, without increasing the risk of hypoglycemia and weight gain, in line with the data from randomized controlled trials $[19,27]$.

The observational design of the current study has limitations such as the lack of a control arm, retrospective data collection methods, non-standardization of reported data 
and possible recall bias for the incidence of hypoglycemia. However, the results obtained are useful for evaluating a treatment in real-life setting rather than in randomized controlled trials in which the data are often influenced by the restricted sample of patients enrolled. Also, observational studies are considered to be more useful in evaluating the post-authorization safety profile of drugs compared with randomized controlled trials [28]. This study included patients on OAD therapy alone and newly diagnosed patients starting IDet + OAD therapy, irrespective of their concomitant medical conditions or other baseline criteria, thus representing situations that communitybased practitioners encounter. The data evaluated in this study may thus be useful in guiding the optimization of $\mathrm{T} 2 \mathrm{D}$ management in routine practice.

\section{CONCLUSION}

In summary, the results of this observational study in the Near East region countries showed that treatment initiation with a long-acting basal analog, IDet, in combination with OAD therapy, can be a safe and effective treatment strategy for T2D patients.

\section{ACKNOWLEDGMENTS}

The authors would like to thank the entire study group, their staff, clinical trial personnel and investigators involved in the study. Special thanks to all the patients and investigators for their participation in this study. The authors would like to thank Dr. Meltem Telaferli, Dr. Vinay Prusty, Dr. Jian-Wen Chen and Chunduo Shen from Novo Nordisk for their support. The authors would also like to thank Ruchita Kapoor from Cognizant Technology Solutions for writing assistance, funded by Novo Nordisk. Dr. Akram Echtay is the guarantor for this article and takes responsibility for the integrity of the work as a whole.

Conflict of interest. Dr Echtay is a member of the speaker's bureau for Novo Nordisk, Sanofi-Aventis, Merck Sharp \& Dohme, Novartis, Pfizer, GSK and Merck (Lebanon), and receives speaker's honoraria. He also participates as a principal investigator in studies sponsored by Novo Nordisk, SanofiAventis, Merck Sharp \& Dohme, Novartis, Astra Zeneca and Merck (Lebanon). Dr Tsur was a principal investigator for this study, sponsored by Novo Nordisk. Dr. Hasan is a member of the Global Advisory Board for the $\mathrm{A}_{1}$ chieve study sponsored by Novo Nordisk. Dr. Abu-Hijleh was the principal investigator for this study, sponsored by Novo Nordisk A/S and has received research grants and speakers honoraria from Sanofi-Aventis, Novartis, Merck Sharp \& Dohme, Servier, Astra Zeneca, Merck, and Pfizer Pharmaceuticals. Dr Khatib is on the advisory panel for Novo Nordisk, Novartis, Pfizer, Merck Sharp \& Dohme, Astra Zeneca and the speaker's bureau for Merck Sharp \& Dohme, Merck Serono, Novo Nordisk, Novartis, Astra-Zeneca and Pfizer. Dr. Andari is on the advisory panel for Novo Nordisk and the speaker's bureau for Merck Sharp \& Dohme, Pfizer, Novartis, Novo Nordisk, Lilly, Astra Zeneca, Boehringer-Ingelheim and Sanofi Aventis. Dr Attalah is a member of the advisory board of Novo Nordisk, Astra Zeneca and Novartis and conducts lectures for Eli Lilly, Novo Nordisk, Menarini, Merck Sharp \& Dohme, Astra Zeneca, and GlaxoSmithKline. Dr. Sandalci and Mrs. Ademogullari are employees of Novo Nordisk Business Area, Near East. Dr. Haddad is a member of the advisory panel for Novo Nordisk and a member 
of the speakers bureau for Merck Sharp \& Dohme, Merck Serono, Novo Nordisk, Novartis, Astra Zeneca, Menarini, and Ferring. Dr Qureshi, Dr Dagan and Dr Zafar have no conflicts of interest to declare.

Compliance with ethics guidelines. All procedures followed were in accordance with the ethical standards of the responsible committee on human experimentation (institutional and national) and with the Helsinki Declaration of 1975 , as revised in 2000 and 2008. Informed consent was obtained from all patients for being included in the study.

Open Access. This article is distributed under the terms of the Creative Commons Attribution Noncommercial License which permits any noncommercial use, distribution, and reproduction in any medium, provided the original author(s) and the source are credited.

\section{REFERENCES}

1. Niswender K. Early and aggressive initiation of insulin therapy for type 2 diabetes: what is the evidence? Clin Diabetes. 2009;27:60-8.

2. Inzucchi SE, Bergenstal RM, Buse JB, et al. Management of hyperglycaemia in type 2 diabetes: a patient-centered approach. Position statement of the American Diabetes Association (ADA) and the European Association for the Study of Diabetes (EASD). Diabetologia. 2012;55:1577-96.

3. American Diabetes Association. Standards of medical care in diabetes-2011. Diabetes Care. 2011;34(Suppl. 1):S11-61.

4. Davis S, Alonso MD. Hypoglycemia as a barrier to glycaemic control. J Diabetes Complicat. 2004;18:60-8.

5. Home PD, Boulton AJM, Jimenez J, Landgraf R, Osterbrink B, Christiansen JS. Issues relating to the early or earlier use of insulin in type 2 diabetes. Pract Diabetes Int. 2003;20:63-71.
6. Scholtz HE, Pretorius SG, Wessels DH, Becker RH. Pharmacokinetic and glucodynamic variability: assessment of insulin glargine, NPH insulin and insulin ultralente in healthy volunteers using a euglycaemic clamp technique. Diabetologia. 2005;48:1988-95.

7. Keating GM. Insulin detemir: a review of its use in the management of diabetes mellitus. Drugs. $2012 ; 72: 2255-87$.

8. Ferriss JB, Webb D, Chaturvedi N, Fuller JH, IdziorWalus B, EURODIAB Prospective Complications Group. Weight gain is associated with improved glycaemic control but with adverse changes in plasma lipids and blood pressure in type 1 diabetes. Diabet Med. 2006;23:557-64.

9. Plank J, Bodenlenz M, Sinner F, et al. A doubleblind, randomized, dose-response study investigating the pharmacodynamic and pharmacokinetic properties of the long-acting insulin analog detemir. Diabetes Care. 2005;28:1107-12.

10. Mathieu C. Engineering basal insulin-clinical evidence translating to clinical experience. JAPI. 2009;57:16-21.

11. Raslova K, Bogoev M, Raz I, Leth G, Gall MA, Hancu $\mathrm{N}$. Insulin detemir and insulin aspart: a promising basal-bolus regimen for type 2 diabetes. Diabetes Res Clin Pract. 2004;66:193-201.

12. Haak T, Tiengo A, Draeger E, Suntum M, Waldhausl W. Lower within-subject variability of fasting blood glucose and reduced weight gain with insulin detemir compared to NPH insulin in patients with type 2 diabetes. Diabetes Obes Metab. 2005;7:56-64.

13. Khunti K, Caputo S, Damci T, et al; on behalf of the SOLVE Study Group. The safety and efficacy of adding once-daily insulin detemir to oral hypoglycaemic agents in patients with type 2 diabetes in a clinical practice setting in 10 countries. Diabetes Obes Metab. 2012;14:1129-36.

14. Dornhorst A, Lüddeke HJ, Sreenan S, et al; PREDICTIVE Study Group. Insulin detemir improves glycaemic control without weight gain in insulin-naïve patients with type 2 diabetes: subgroup analysis from the PREDICTIVE study. Int J Clin Pract. 2008;62:659-65.

15. Diabetes Federation. IDF Diabetes Atlas. 5th ed. Brussels, Belgium; 2011, updated 14 November 2012. http://www.idf.org/diabetesatlas/5e. Accessed 23 September 2013.

16. Whiting DR, Guariguata L, Weil C, Shaw J. IDF diabetes atlas: global estimates of the prevalence of 
diabetes for 2011 and 2030. Diabetes Res Clin Pract. 2011;94:311-21.

17. Nathan DM, Buse JB, Davidson MB, et al; American Diabetes Association; European Association for Study of Diabetes. Medical management of hyperglycemia in type 2 diabetes: a consensus algorithm for the initiation and adjustment of therapy: a consensus statement of the American Diabetes Association and the European Association for the Study of Diabetes. Diabetes Care. 2009;32:193-203.

18. Breum L, Almdal T, Eiken P, Lund P, Christiansen E, Danish BIAsp Study Group. Initiating or switching to biphasic insulin aspart 30/70 therapy in subjects with type 2 diabetes mellitus. An observational study. Rev Diabet Stud. 2008;5(3):154-62.

19. Rosenstock J, Davies M, Home PD, Larsen J, Koenen C, Schernthaner G. A randomised, 52-week, treat-to-target trial comparing insulin detemir with insulin glargine when administered as add-on to glucose-lowering drugs in insulinnaive people with type 2 diabetes. Diabetologia. 2008;51(3):408-16.

20. Swinnen SG, Dain MP, Aronson R, et al. A 24-week, randomized, treat-to-target trial comparing initiation of insulin glargine once-daily with insulin detemir twice-daily in patients with type 2 diabetes inadequately controlled on oral glucoselowering drugs. Diabetes Care. 2010;33(6):1176-8.

21. Mäkimattila S, Nikkilä K, Yki-Järvinen H. Causes of weight gain during insulin therapy with and without metformin in patients with type II diabetes mellitus. Diabetologia. 1999;42:406-12.

22. Raslová K, Tamer SC, Clauson P, Karl D. Insulin detemir results in less weight gain than NPH insulin when used in basal-bolus therapy for type 2 diabetes mellitus, and this advantage increases with baseline body mass index. Clin Drug Investig. 2007;27:279-85.

23. Hermansen K, Davies M. Does insulin detemir have a role in reducing risk of insulin-associated weight gain? Diabetes Obes Metab. 2007;9:209-17.

24. Peterson GE. Analog insulin detemir for patients with type 1 and type 2 diabetes: a review. Diabetes Metab Syndr Obes. 2009;2:31-6.

25. Wright A, Burden ACF, Paisey RB, Cill CA, Holman $\mathrm{RR}$, and the UK Prospective Diabetes Study Group. Sulphonylurea inadequacy: efficacy of addition of insulin over 6 years in patients with type 2 diabetes in the UK. Prospective Diabetes Study (UKPDS 57). Diabetes Care. 2002;25:330-6.

26. Riedel AA, Heien $\mathrm{H}$, Wogen $\mathrm{J}$, Plauschinat CA. Secondary failure of glycemic control for patients adding thiazolidinedione or sulphonylurea therapy to metformin regimen. Am J Manag Care. 2007; 13: 457-63.

27. Hermansen K, Davies M, Derezinski T, Martinez Ravn G, Clauson P, Home P. A 26-week, randomized, parallel, treat-to-target trial comparing insulin detemir with NPH insulin as add-on therapy to oral glucose-lowering drugs in insulin-naive people with type 2 diabetes. Diabetes Care. 2006;29(6):1269-74.

28. Vandenbroucke JP. What is the best evidence for determining harms of medical treatment? CMAJ. 2006;174:645-6. 